\title{
Mental Health and Self-Determination Profiles of the Diverse Population of Medical Students in Malaysia During the COVID-19 Pandemic
}

\author{
Jessica Cockburn \\ Universiti Malaya \\ Chee Yang Tan \\ Universiti Malaya \\ Dawn Celine Siaw Chern Poh \\ Newcastle University Medicine Malaysia \\ Ding Jun Tan \\ Universiti Malaya \\ Chan Choong Foong \\ Universiti Malaya \\ Wei-Han Hong ( $\nabla$ weihan@um.edu.my ) \\ Universiti Malaya
}

\section{Research Article}

Keywords: COVID-19, self-determination, diversity, undergraduate medical education, autonomy, relatedness, competence, mental health, well-being

Posted Date: December 2nd, 2021

DOl: https://doi.org/10.21203/rs.3.rs-1094460/v1

License: (9) This work is licensed under a Creative Commons Attribution 4.0 International License. Read Full License

Version of Record: A version of this preprint was published at BMC Psychology on March 3rd, 2022. See the published version at https://doi.org/10.1186/s40359-022-00759-y. 


\section{Abstract}

Introduction: Medical schools throughout the world were forced to modify their programming during the COVID-19 pandemic. In Malaysia, virtual learning plans were implemented for non-clinical programming, while clinical posting modifications were designed to meet local SOPs. The prolonged enforcement of these modifications to undergraduate medical education will have affected student experiences, including well-being. Since these feelings can relate to perceived relatedness, autonomy, and competence, it is important to identify any potential factors that may lead to reduced intrinsic motivation in students. It is also important to consider how demographic features may contribute to student perspectives, which can be studied using the unique diversity represented by Malaysian students.

Methods: A quantitative survey was distributed to Malaysian medical students to assess their overall wellbeing, autonomy in educational decision making, student experiences, and position on changes to graduation timing. Intrinsic components were identified using Principal Component Analysis and were aligned with the three needs for self-determination, namely relatedness, autonomy, and competence. Finally, trends in responses for participants from various sub-populations were assessed using ANOVA testing.

Results: Responses were collected from 442 students representing 23 accredited Malaysian medical schools. Upon validation and reliability testing, eight components were identified with themes relating to: mental health, social concerns, communication, timing of modifications, depth of learning, and student-centred learning. Of these, gender was related to mental health, student-centred learning, and delayed graduation, while stage was related to student-centred learning and delayed graduation in addition to concerns about depth of learning and timing of modifications. Interestingly, ethnicity was related to differences in opinions about delayed graduation and income was related to social concerns.

Conclusion: The results of this study indicate that, while students were satisfied in general with the content and delivery of their programmes given the circumstances, there is evidence to suggest negative effects on emotional wellbeing, expression of student voice, due to the modifications that were made. Additionally, these feelings related to the three motivational needs, suggesting that students were experiencing a dampened motivational profile during the pandemic. Further, motivational profiles were distinct between student sub-groups, providing insight for developing appropriate and inclusive accommodations moving forward.

\section{Background}

In 2020, Malaysia was facing the challenges of a global pandemic due to the widespread transmission of the novel SARS-CoV-2. To mitigate this spread, the Malaysian government implemented strict lockdown protocols including the conversion of face-to-face educational programmes to virtual learning environments, including the non-clinical delivery of medical education. To meet these requirements, undergraduate medical programmes in Malaysia (MBBS) provided students with online-based courses, and modified student requirements in clinical postings. The national response in 2020 afforded relatively good control over the number of COVID19 cases, but, despite evolving restrictions, cases gradually rose through 2021, resulting in a corresponding burden on the healthcare system [1]. During this time, non-clinical teaching remained virtual, while clinical postings were adapted depending on context.

There are currently 30 accredited undergraduate medical schools in Malaysia which offer five-year degrees for high school leavers. Each programme is divided into pre-clinical and clinical stages, with an increasing weightage of workplace-based learning during clinical stages, and are overseen by the Malaysian Qualification Agency (MQA) and the Malaysian Medical Council (MMC). The student population reflects the diversity in Malaysia, which is predominantly comprised of three ethnic groups and includes a range of socioeconomic brackets. However, the programmes vary between institutions to accommodate access to resources, geographical location, funding schemes (i.e. public vs. private), and affiliations with hospital settings, among other features. These differences have resulted in the need for each institution to interpret restrictions and customize modifications, while adhering to quality assurance guidelines set by both the MQA and MMC to maintain programme integrity [2].

The rapid transition to online learning in medical education globally required synchronous virtual learning environments, supported by various platforms and modifications specific to each institute's resources and clinical requirements [3-8]. These virtual learning strategies have been validated as appropriate alternatives for educational delivery and while most participants may prefer physical

Page 2/18 
lessons, there is a consensus that content delivery online is adequate and may even promote flexibility in pacing [9-13]. However, challenges may arise from technical resource availability or low levels of digital literacy $[6,13]$. In addition to virtual learning modifications for non-clinical programme components, clinical postings required additional modifications to reduce COVID-19 risk for students [14]. While the response of medical schools globally has been varied, it has included changes to graduation, reducing the amount of clinical practice time, and transition to virtual assessments, while trying to minimize the need to suspend placements [15-18]. There has been an attempt to standardize these actions in the medical education community to maintain quality as the pandemic continues and to prepare for future disruptions [17, 19-21].

It is important to understand the impact of pandemic-related modifications on student learning experiences and wellbeing. This is particularly true in Malaysia where the fluctuating COVID-19 situation has led to long-term reliance on virtual learning and frequent changes in modifications, both of which have the potential to impact wellbeing. The use of virtual platforms creates both physical and social separation, and act as "virtual walls". Naturally, increasing physical distance has been important to reduce the spread of infection, but it has also been associated with a reduction in the quality and quantity of interactions between peers and instructors, leading to feelings of isolation [22]. Also, it has been shown that using virtual learning for extended periods can lead to feelings of withdrawal and lowered motivation, particularly if students are not accustomed to, prepared for, or anticipated this learning style [23, 24]. Thus, it is essential to assess the mental health and wellbeing of students to provide supports that reflect student needs for effective learning and optimal motivation.

Full-time students in Malaysia have had to endure lengthy restrictions and educational modifications, potentially impacting wellbeing and mental health and in turn, affect the three basic psychological needs for intrinsic motivation [25-27]. A sense of autonomy may be lost in students who have faced a virtual wall and reduced ability to communicate with peers, instructors, and administrators. Challenges to communication are compounded by rapid response needed to implement new modifications to meet fluctuating restrictions, where time and logistics make it difficult for students to provide input. The virtual wall also reduces the quality and quantity of interactions amongst peers and instructors, reducing relatedness by increasing feelings of separation and isolation. Additionally, changes to expectations and experiences are known to dampen mental wellbeing and feelings of relatedness [28]. Finally, ineffective delivery of education, particularly in regions with technical challenges or for those who have limited digital literacy [29], may result in students' feelings of inadequacy or lowered perceived competence. Given that each of these motivational needs have potentially been impacted, there should be concern about the effects of low motivation, which may lead to attrition, burnout, or unprepared students.

The Malaysian context during the COVID-19 pandemic provides a unique opportunity to examine how a diverse group of undergraduate medical students have experienced the COVID-19 pandemic. This can provide important insight about the shared and unique perspectives from various ethnographic populations. The goal of this study was to capture the perceptions of Malaysian medical students regarding impacts of the pandemic on their education and discern whether these experiences relate to major demographic variables. To do this, a questionnaire was designed with the intent to measure their perceived mental wellbeing and physical health risks, autonomy in decision making, perceived implications of distance learning on their education, and provide insight to changes that may affect graduation. An opportunity was also taken to assess the experiences and perceptions of clinical students about participation and safety in clinical postings during the COVID-19 pandemic. Here, the effects on student wellbeing and motivational profiles of the student population and within different subgroups are shown.

\section{Methods}

\section{Study Population}

All undergraduate medical students actively registered in accredited medical schools within Malaysia were entitled to participate in the study, including both public and private institutions. Power estimates required that at least 341 responses were required to achieve a representative sample with confidence level of $95 \%$ and 0.05 margin of error, based on an estimated student population of 3,000 in Malaysia. Ethics approval was obtained from the Universiti Malaya Research Ethics Committee (UMREC)

(UM.TNC2/UMREC_1241). Invitations to participate were distributed through the Society of Malaysian Medical Association Medical Students (SMMAMS) contacts with the accredited medical school student groups in Malaysia. 
Instrument Design: An online cross-sectional survey was designed using the framework from the Association for Medical Education in Europe (AMEE) Guide No. 87 [30]. Specifically, items were phrased using positive phrasing and likert-scales were used such that low values tended towards a negative alignment (i.e. "never") and high values tended towards a positive alignment (i.e. "always"). The survey was composed of a demographic section, and seven sub-sections including those related to: wellness and concerns, experience with online learning, involvement in decision making, teaching and learning, assessment, graduation expectations, and a clinical-student section. Four items from the Patient Health Questionnaire-2 (PHQ-2) and Generalized Anxiety Disorder 2-item (GAD2) screening tools for Major Depressive Disorder (MDD) and Generalized Anxiety Disorder (GAD), respectively [31, 32]. Other items were designed by the authors and reviewed by local experts. Items were selected to minimize length of the survey and to align with research objectives as piloting was not possible given time restraints.

\section{Statistical Analysis}

Data was prepared for analysis by removing incomplete surveys, if more than two subsections were incomplete, and items, if more than $10 \%$ of participants did not provide a response. Responses were codified using numerical values to represent variables. Statistical analysis was done using the IBM SPSS statistic package version 23.0. Items were validated using Principal Component Analysis (PCA) using varimax rotation. Validity was granted when the Kaiser-Meyer Olkin (KMO) was $\geq 0.70$ and the Bartlett's Test of sampling adequacy was significant $(p \leq 0.05)$ [33]. Components were selected if eigen-values were $\geq 1.0$ (Campbell 2002). Items within the components required average communicality after extraction to be $\geq 0.60$, given a sample size greater than 250 (Field 2009). Further, items required factor loading of $\geq 0.50$ and those with cross-loadings $\leq 0.50$ were excluded from analysis (Maskey 2018). Internal consistency of the survey was calculated using Cronbach's $a$ and considered sufficient if $a \geq 0.50$ (Bowling 2009, Verma 2010). The resulting set of corrected items required the item-total correlation to be $\geq 0.20$ and the leave-one-out Cronbach a coefficient to not be significantly changed (i.e. $a \leq 0.50)$ (Verma 2010).

Descriptive statistics were calculated for demographic variables and component scores. Component scores were calculated by averaging the responses within the component. Four items were reverse coded (PHQ and GAD items), which were inversed to calculate the component score. PHQ score and GAD scores were calculated as described previously [31, 32]. Data distribution was assessed for normality. T-Test and ANOVA calculations were used to assess whether responses were significantly different $(p<0.05)$ between two or more groups, respectively. Strength of correlations between demographic variables were determined using Pearson correlation coefficients $\left(\mathrm{r}^{2}\right)$.

Qualitative Analysis: Respondents were invited to provide additional written comments, which were extracted and coded using thematic analysis. Thematic analysis was conducted in six steps: (1) the data was read several times to be familiarized with the data, (2) initial codes were generated for repeated or interesting comments, (3) initial codes were consolidated, and themes were identified, (4) the themes were reviewed and cross-checked with quoted comments, (5) the themes were named and defined, and (6) the themes were presented as findings of this study [34].

\section{Results}

Survey Collection: Between March 23rd-June 3rd, 2021, 453 students responded representing 23 of 30 public and private accredited institutions across Malaysia. In total, 9 participant surveys and one item were missing more than $5 \%$ of responses and were removed from the study. Any remaining missing data was assessed pairwise.

Demographics: The cohort of students represented a variety of demographic variables (Table 1). Students were self-assigned into pre-clinical $(61.5 \% \mathrm{n}=273)$ and clinical $(38.5 \% \mathrm{n}=171)$ stages of their undergraduate programmes. Females were represented by $66.3 \%$ of respondents and the average age was $20.84(\sigma=1.77)$. The ethnic profile of students represented Malay $(28.2 \%)$, Chinese (53.5\%), Indian (12.3\%), and International (6\%) cultures. Additionally, socio-economic status of students was measured using three cut points relating to tertiles of household income, specifically those below the 40th percentile (B40; 15.2\%), within the middle 40th percentile (M40; 61.0\%), and above the 20th percentile (T20;23.8\%). Demographic variables were not significantly correlated. 
Table 1. Demographic Variables

\begin{tabular}{|c|c|c|c|}
\hline & & $\mathbf{n}$ & Central Tendency \\
\hline Age & & 436 & $20.84(1.77)^{\star}$ \\
\hline \multirow[t]{3}{*}{ Stage } & & 444 & \\
\hline & Preclinical & 273 & $61.5 \%$ \\
\hline & Clinical & 171 & $38.5 \%$ \\
\hline \multirow[t]{4}{*}{ Gender } & & 433 & \\
\hline & Male & 144 & $33.3 \%$ \\
\hline & Female & 287 & $66.3 \%$ \\
\hline & Non-binary & 2 & $0.5 \%$ \\
\hline \multirow[t]{5}{*}{ Ethnicity } & & 415 & \\
\hline & Malay & 117 & $28.2 \%$ \\
\hline & Chinese & 222 & $53.5 \%$ \\
\hline & Indian & 51 & $12.3 \%$ \\
\hline & International & 25 & $6.0 \%$ \\
\hline \multirow[t]{4}{*}{ Income } & & 447 & \\
\hline & Below 40th Percentile & 65 & $15.2 \%$ \\
\hline & Middle 40th Percentile & 261 & $61.0 \%$ \\
\hline & Top 20th Percentile & 102 & $23.8 \%$ \\
\hline
\end{tabular}

Components: Demographic, categorical, tick-box, and qualitative items were removed for PCA. Convergence between the remaining 40 items was met after 4 iterative rounds of PCA, resulting in eight components comprising 32 items in total $(K M O=0.802, p<0.000)$. Internal consistency was estimated for all items combined ( $a=0.622)$ and using leave-one-out analysis of each item ( $a \geq 0.50$ for all). The items within the resulting components were thematically related to: Mental Health, Depth of Learning, Social Concern, Communication, Timing, Delayed Graduation, Assignments, and Student-Centred Learning (Table 2.). The dataset that includes average responses for each item within the components, which support the conclusions of this article are available in Additional file 1.

Wellbeing: Student mental health was assessed using the PHQ-2 and GAD-2 items, which indicated that $45 \%$ of students were likely to be experiencing MDD or GAD (Figure 1.). These were captured in Component 1, which reflected responses from students reporting little interest, feeling depressed, or the inability to control worrying for at least several days in the prior two weeks (Table 2.). Female students were more likely to respond negatively overall towards their mental health $(p<0.000)$ (Table 2 .) and were at a significantly higher risk of MDD and GAD ( $<0.000)$ (Table 3.). Ethnicity was also related to mental health, as Chinese students indicated having better mental health compared to the remaining students' average $(p<0.000)(T a b l e 1$.). Additionally, students provided qualitative comments regarding concerns about their own or their peers mental health (Table 4.) 
Table 2. Average component scores by selected demographic variables

\begin{tabular}{|c|c|c|c|c|c|c|c|c|c|}
\hline & & $\begin{array}{l}\text { Mental } \\
\text { Health }\end{array}$ & $\begin{array}{l}\text { Depth of } \\
\text { Learning }\end{array}$ & Concern & Communication & Timing & Graduation & $\begin{array}{l}\text { Virtual } \\
\text { Assessment }\end{array}$ & $\begin{array}{l}\text { Student- } \\
\text { Centred } \\
\text { Learning }\end{array}$ \\
\hline & & $\mathrm{C} 1$ & $\mathrm{C} 2$ & C3 & $\mathrm{C} 4$ & C5 & $\mathrm{C} 6$ & $\mathrm{C} 8$ & C9 \\
\hline \multirow[t]{2}{*}{ All Students } & Mean & 2.81 & 2.18 & 3.02 & 2.58 & 3.47 & 3.23 & 2.66 & 3.34 \\
\hline & SD & 0.80 & 0.65 & 0.90 & 0.76 & 0.57 & 1.10 & 1.44 & 0.80 \\
\hline \multicolumn{10}{|l|}{ Stage } \\
\hline \multirow[t]{2}{*}{ Pre-Clinical } & Mean & 2.82 & $2.26 *$ & 3.03 & 2.60 & $3.39 *$ & $3.07 *$ & 2.73 & $3.20 *$ \\
\hline & SD & 0.76 & 0.63 & 0.85 & 0.78 & 0.49 & 1.08 & 1.53 & 0.74 \\
\hline \multirow[t]{3}{*}{ Clinical } & Mean & 2.88 & $2.06 *$ & 3.00 & 2.57 & $3.60 *$ & $3.47 *$ & 2.56 & $3.55^{\star}$ \\
\hline & SD & 0.86 & 0.65 & 0.98 & 0.74 & 0.65 & 1.09 & 1.27 & 0.86 \\
\hline & $p$ & & 0.002 & & & 0.000 & 0.000 & & 0.000 \\
\hline \multicolumn{10}{|l|}{ Gender $^{a}$} \\
\hline \multirow[t]{2}{*}{ Male } & Mean & $3.10 *$ & 2.27 & 2.93 & 2.51 & 3.41 & 3.07 & 2.71 & $3.50 *$ \\
\hline & SD & 0.71 & 0.65 & 0.84 & 0.73 & 0.57 & 1.10 & 1.48 & 0.78 \\
\hline \multirow[t]{3}{*}{ Female } & Mean & $2.73 *$ & 2.14 & 3.06 & 2.63 & 3.49 & 3.28 & 2.59 & $3.26 *$ \\
\hline & SD & 0.82 & 0.64 & 0.93 & 0.78 & 0.56 & 1.10 & 1.40 & 0.81 \\
\hline & $p$ & 0.000 & & & & & & & 0.013 \\
\hline \multicolumn{10}{|l|}{ Ethnicity } \\
\hline \multirow[t]{2}{*}{ Malay } & Mean & $2.60 *$ & 2.10 & 3.11 & 2.68 & 3.40 & $3.35^{\star}$ & 2.80 & 3.30 \\
\hline & SD & 0.78 & 0.67 & 0.86 & 0.72 & 0.57 & 0.99 & 1.39 & 0.78 \\
\hline \multirow[t]{2}{*}{ Chinese } & Mean & $3.05^{*}$ & 2.23 & 2.93 & 2.59 & 3.48 & $3.25^{\star}$ & 2.50 & 3.36 \\
\hline & SD & 0.73 & 0.57 & 0.91 & 0.79 & 0.55 & 1.10 & 1.41 & 0.81 \\
\hline \multirow[t]{2}{*}{ Indian } & Mean & $2.74^{*}$ & 2.34 & 3.12 & 2.45 & 3.51 & $2.75^{\star}$ & 2.71 & 3.33 \\
\hline & SD & 0.82 & 0.86 & 0.89 & 0.60 & 0.66 & 1.14 & 1.61 & 0.80 \\
\hline \multirow[t]{3}{*}{ International } & Mean & $2.32^{*}$ & 2.01 & 3.21 & 2.36 & 3.51 & $3.11 *$ & 2.44 & 3.50 \\
\hline & SD & 0.93 & 0.73 & 0.96 & 0.95 & 0.55 & 1.32 & 1.39 & 0.76 \\
\hline & $p$ & 0.000 & & & & & 0.013 & & \\
\hline \multicolumn{10}{|l|}{ Income } \\
\hline \multirow[t]{2}{*}{ B40 } & Mean & 2.77 & 2.10 & $3.14 *$ & 2.56 & 3.46 & 3.33 & 2.70 & 3.30 \\
\hline & SD & 0.90 & 0.57 & 0.92 & 0.63 & 0.50 & 1.07 & 1.47 & 0.95 \\
\hline \multirow[t]{2}{*}{ M40 } & Mean & 2.86 & 2.17 & $3.05^{\star}$ & 2.51 & 3.46 & 3.29 & 2.74 & 3.36 \\
\hline & SD & 0.79 & 0.69 & 0.90 & 0.77 & 0.59 & 1.13 & 1.46 & 0.80 \\
\hline \multirow[t]{3}{*}{ T20 } & Mean & 2.82 & 2.21 & $2.80 *$ & 2.71 & 3.49 & 3.07 & 2.49 & 3.29 \\
\hline & SD & 0.77 & 0.58 & 0.87 & 0.80 & 0.55 & 1.02 & 1.37 & 0.76 \\
\hline & $p$ & & & 0.026 & & & & & \\
\hline
\end{tabular}


*Indicate mean scores that are significantly different from at least one other variable $(p<0.05)$

a. Non-binary students excluded due to the small sample size

Abbreviations: SD-Standard Deviation; B40-Bottom 40 th percentile; M40-Middle $40^{\text {th }}$ percentile; T20-Top $20^{\text {th }}$ percentile; CComponent

Student wellbeing was also assessed by asking students about their concerns and worries in factors related to contracting COVID19 and its transmission to self, peers or instructors, or family. Students mostly reported minimal to moderate concern, which related to their physical wellbeing if they were to be infected with SARS-CoV-2 or in working at clinical environments (Component 3.; Table 2.). Interestingly, most students expressed high levels of worry regarding peers or instructors developing COVID-19 $(\mu=3.03, \sigma=1.18)$ (Table 3.). Concern was also significantly associated with income, as those in lower income brackets indicated more concern overall $(p=0.026)$ (Table 2.) and with regards to financial impact of the pandemic $(P<0.000)($ Table 3.). Within Component 3 , ethnicity was related to concern about family members developing COVID-19 $(p=0.004)$ (Table 3.). 
Table 3. Selected item descriptors by subgroup

\begin{tabular}{|c|c|c|c|c|c|}
\hline Grouping & Item & Variable & Mean & SD & $p$ \\
\hline \multirow[t]{9}{*}{$\begin{array}{l}\text { All } \\
\text { Students }\end{array}$} & $\begin{array}{l}\text { How much have students been able to contribute to modifications in the } \\
\text { medical program during the COVID-19 pandemic? }\end{array}$ & - & 2.48 & 1.03 & - \\
\hline & $\begin{array}{l}\text { Do you think program administrators consider your overall well-being } \\
\text { when considering modifications to the medical program? }\end{array}$ & - & 2.44 & 0.98 & - \\
\hline & $\begin{array}{l}\text { Do you consciously worry about your peers/instructors developing } \\
\text { COVID-19? }\end{array}$ & - & 3.03 & 1.18 & - \\
\hline & Do you feel that you are being prepared for your profession? & - & 2.00 & 0.88 & - \\
\hline & $\begin{array}{l}\text { Do you feel that virtual assessments accurately measure your } \\
\text { theoretical knowledge? }\end{array}$ & - & 3.02 & 0.98 & - \\
\hline & $\begin{array}{l}\text { Do you feel that virtual assessments accurately measure your clinical } \\
\text { skills? }\end{array}$ & - & 1.94 & 0.93 & - \\
\hline & $\begin{array}{l}\text { Do you feel that virtual assessments accurately measure your } \\
\text { professionalism? }\end{array}$ & - & 2.28 & 1.03 & - \\
\hline & Concerned about a delays on preparedness & - & 2.94 & 1.32 & - \\
\hline & Do you consciously worry about your family developing COVID-19? & - & 3.84 & 1.15 & - \\
\hline \multirow[t]{18}{*}{ Stage } & \multirow{2}{*}{$\begin{array}{l}\text { What percent of time have you spent using online learning environments } \\
\text { since March 2020? }\end{array}$} & Pre-Clinical & 4.72 & 0.76 & 0.000 \\
\hline & & Clinical & 4.40 & 0.92 & \\
\hline & \multirow{2}{*}{$\begin{array}{l}\text { Are you concerned about a delayed graduation on your preparedness for } \\
\text { the profession? }\end{array}$} & Pre-Clinical & 2.76 & 1.31 & 0.000 \\
\hline & & Clinical & 3.22 & 1.29 & \\
\hline & \multirow{2}{*}{$\begin{array}{l}\text { Do you think program administrators consider your overall well-being } \\
\text { when considering modifications to the medical program? }\end{array}$} & Pre-Clinical & 2.53 & 1.03 & 0.015 \\
\hline & & Clinical & 2.29 & 0.88 & \\
\hline & \multirow{2}{*}{$\begin{array}{l}\text { Overall, are you satisfied with the delivery of medical education during } \\
\text { the COVID-19 pandemic? }\end{array}$} & Pre-Clinical & 2.45 & 0.97 & 0.004 \\
\hline & & Clinical & 2.17 & 0.98 & \\
\hline & \multirow{2}{*}{$\begin{array}{l}\text { Are you concerned about your ability to secure housemanship after } \\
\text { graduation based on modifications to your programming made during } \\
\text { the pandemic? }\end{array}$} & Pre-Clinical & 3.38 & 1.18 & 0.003 \\
\hline & & Clinical & 3.72 & 1.19 & \\
\hline & \multirow[t]{2}{*}{ PHQ2 Score } & Pre-Clinical & 2.31 & 1.55 & 0.039 \\
\hline & & Clinical & 1.98 & 1.75 & \\
\hline & \multirow{2}{*}{$\begin{array}{l}\text { Do you feel that virtual assessments accurately measure your } \\
\text { theoretical knowledge? }\end{array}$} & Pre-Clinical & 3.12 & 0.095 & 0.006 \\
\hline & & Clinical & 2.85 & 1.06 & \\
\hline & \multirow{2}{*}{$\begin{array}{l}\text { Do you feel that virtual assessments accurately measure your clinical } \\
\text { skills? }\end{array}$} & Pre-Clinical & 2.06 & 0.94 & 0.000 \\
\hline & & Clinical & 1.74 & 0.89 & \\
\hline & \multirow{2}{*}{$\begin{array}{l}\text { Do you feel that virtual assessments accurately measure your } \\
\text { professionalism? }\end{array}$} & Pre-Clinical & 2.37 & 1.006 & 0.026 \\
\hline & & Clinical & 2.15 & 1.04 & \\
\hline \multirow[t]{5}{*}{ Gender } & \multirow{2}{*}{$\begin{array}{l}\text { Are you concerned about a delayed graduation on your preparedness for } \\
\text { the profession? }\end{array}$} & Male & 2.69 & 1.29 & 0.008 \\
\hline & & Female & 3.05 & 1.32 & \\
\hline & \multirow[t]{2}{*}{ PHQ2 Score } & Male & 1.74 & 1.42 & 0.000 \\
\hline & & Female & 2.37 & 1.69 & \\
\hline & GAD2 Score & Male & 1.42 & 1.56 & 0.000 \\
\hline
\end{tabular}




\begin{tabular}{|c|c|c|c|c|c|}
\hline & & Female & 2.36 & 1.86 & \\
\hline & \multirow[t]{2}{*}{ Would you like the teaching to be more interactive? } & Male & 3.72 & 1.03 & 0.006 \\
\hline & & Female & 3.38 & 1.08 & \\
\hline \multirow[t]{16}{*}{ Ethnicity } & \multirow[t]{4}{*}{ Do you consciously worry about your family developing COVID-19? } & Malay & 4.08 & 1.02 & 0.004 \\
\hline & & Chinese & 3.65 & 1.19 & \\
\hline & & Indian & 3.96 & 1.02 & \\
\hline & & International & 4.08 & 1.19 & \\
\hline & \multirow[t]{4}{*}{ Do you feel that you are being prepared for your profession? } & Malay & 1.89 & 0.95 & 0.000 \\
\hline & & Chinese & 1.92 & 0.77 & \\
\hline & & Indian & 2.54 & 0.95 & \\
\hline & & International & 2.20 & 1.00 & \\
\hline & \multirow{4}{*}{$\begin{array}{l}\text { Are you able to communicate concerns about SOPs to coordinators (or } \\
\text { those overseeing your postings)? }\end{array}$} & Malay & 3.19 & 1.02 & 0.004 \\
\hline & & Chinese & 2.99 & 1.18 & \\
\hline & & Indian & 2.13 & 0.72 & \\
\hline & & International & 2.50 & 1.03 & \\
\hline & \multirow[t]{4}{*}{ PHQ2 Score } & Malay & 2.55 & 1.65 & 0.001 \\
\hline & & Chinese & 1.92 & 1.51 & \\
\hline & & Indian & 2.24 & 1.66 & \\
\hline & & International & 2.96 & 1.99 & \\
\hline \multirow[t]{6}{*}{ Income } & \multirow{3}{*}{$\begin{array}{l}\text { Are you concerned about the direct financial impact of the pandemic on } \\
\text { you or your family? }\end{array}$} & B40 & 3.69 & 1.27 & 0.000 \\
\hline & & M40 & 3.41 & 1.28 & \\
\hline & & T20 & 2.84 & 1.30 & \\
\hline & \multirow{3}{*}{$\begin{array}{l}\text { Do you receive feedback for improvement from your instructors } \\
\text { currently, during the pandemic? }\end{array}$} & B40 & 2.66 & 0.91 & 0.019 \\
\hline & & M40 & 2.70 & 1.05 & \\
\hline & & T20 & 3.02 & 1.04 & \\
\hline
\end{tabular}


Table 4. Representative qualitative student responses

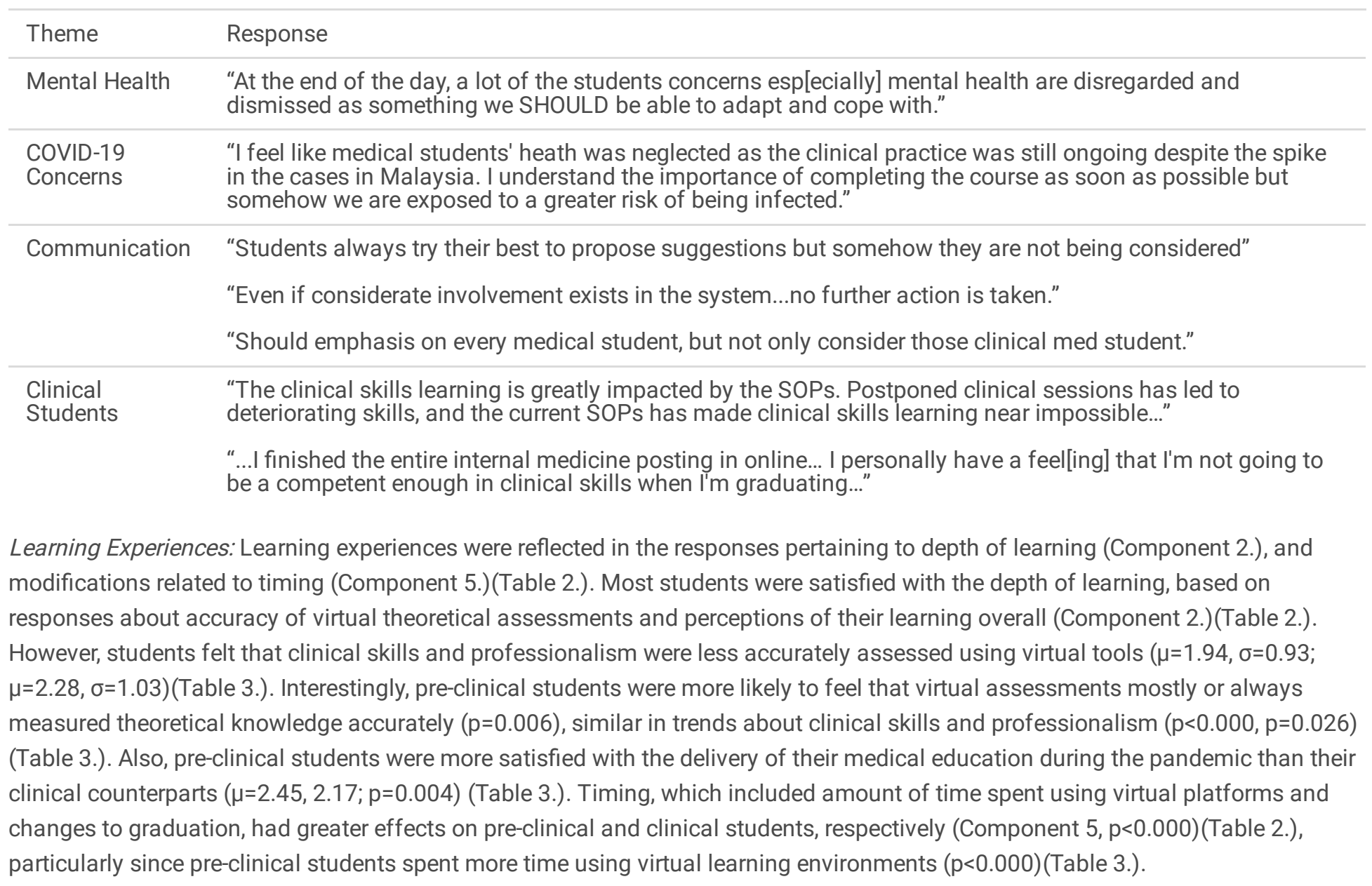

The amount of interactivity and ability to ask questions in class was reflected by the student-centred learning component (Component 9), such that most students indicated that they could minimally or never ask questions and that they would like to have more interactive teaching (Table 2.). Pre-clinical students experienced less student-centred learning than clinical students ( $p<0.000)$ (Table 2.).

Future Readiness: Preparedness arose in the components related to depth of learning (Component 2) and graduation (Component $6)$. On average, students felt that they were only being prepared 'a little bit' for their profession $(\mu=2.00 ; \sigma=0.880)$ and clinical students felt significantly less prepared based on changes to graduation (Component $6, p<0.000)($ Table 3 .). Indian students felt that they were being more prepared for their profession $(p=0.000)$, while female students felt that changes made to graduation would result in less preparedness, compared than their respective counterparts $(p=0.008)$ (Table 3.). Further, students indicated some concern about effects of delayed graduation on preparedness, but pre-clinical students indicated less concern about securing horsemanship based on delayed graduation than clinical students $(p<0.00)($ Table 3 .).

Communication: Students reported to receive limited communication (Component 4), which included a lack of feedback from instructors (Table 2.). Specifically, income was related to perceived levels of feedback, as those in lower income brackets indicated receiving less feedback ( $p=0.019$ ) (Table 3.). Also, students reported to have been moderately consulted about modifications made to programming during the pandemic and students indicate that their wellbeing was being adequately considered during decision making (Table 3.). Additionally, more pre-clinical students felt that their wellbeing was being considered in decision making compared to clinical students $(p=0.015)$ (Table 3.). A number of students provided comments regarding a lack of consideration or inclusion in the decision making process (Table 4.)

Clinical Subsection: Clinical students responded to items about communication, safety, and participation in their clinical postings. Most clinical students felt they were at least sometimes able to communicate concerns about SOPs with coordinators (Figure 2.). Differences existed in the degree of ability to communicate based on ethnicity $(p=0.011)($ Table 3 .). Importantly, $45 \%$ of students felt 
that there were safety concerns in their clinical postings, though a majority of students indicated that they should at least mostly participate (Figure 2.). Some students commented about the effects of SOPs on the quality of their clinical postings (Table 4.).

Qualitative Findings: There were 83 participants who provided optional comments that were used for thematic analysis. Three major themes were identified including: student concerns for overall health (Wellness), challenges with student involvement in medical curricula modifications (Communication), and interruptions to the clinical portion of the MBBS programmes (Clinical Posting Interruptions) (Table 4.).

\section{Discussion}

The COVID-19 pandemic affected medical schools worldwide, requiring schools to respond quickly by adapting to virtual learning environments and by modifying clinical placements. Medical students were expected to manage these changes in addition to the universal challenges of a global crisis, giving them a unique perspective during the pandemic. The population of Malaysia includes three major ethnicities and a broad distribution of socioeconomic groupings, which is reflected by the medical student population. By surveying all medical students in Malaysia, it was possible to characterize the perspectives shared by students nationally and those which may be related to specific ethnographic groups. The results indicate that student perceptions converge on eight domains relating to well-being, depth of learning experience, and communication. Interestingly, none of the components included items relating to technical delivery of virtual learning, suggesting that any technical challenges were independent of the pandemicrelated experiences of students and are not an underlying factor in student well-being or motivation $[6,13]$.

The components identified in this study align with self-determination theory and help to understand the intrinsic motivation of students during the pandemic. Of concern, a large percent of students met the risk threshold for experiencing MDD or GAD. This was supported by claims about having depressed or anxious symptoms and experiencing considerate, or even overwhelming, concern and was validated through student comments. While baseline mental health and wellness are unknown, students did comment that their mental health has been negatively affected by the pandemic, as seen elsewhere $[13,35,36]$. Importantly, levels of mental health and wellbeing, which are intricately related to each psychological need, suggesting that motivation may also be low[37]. Results like these have been of concern, as the reduction in mental health will also affect both student learning and personal satisfaction $[25,38,39]$. Indeed, strategies to improve student well-being and maintain motivation are being developed to specifically target students emotionally affected by pandemic-related restrictions [40].

While well-being may affect each motivational need, other components corresponded to specific needs. Communication, for example, is required for relatedness and autonomy, as the interaction with others can promote emotional connectedness and independence, respectively [41,42]. Communication is also integral to education, making it an important measure of the effectiveness of instruction and experiences of students. Here, students provided negative sentiments about engagement in the classroom and formative and summative assessment, suggesting that communication with instructors has been impeded and may indicate low feelings of relatedness [43]. Similarly, while students some consultation in decision making about pandemic-related modifications, numerous comments regarding the student role, or lack thereof, in decision-making processes, suggesting that student choice may not have been implemented. This overall reduction in communication suggests that students feel that they are not being validated, subsequently leading to reduced autonomy and motivation [44]. This is supported by reported evidence that positive relationships with instructors and being provided choice are related to feelings of autonomy $[42,45,46]$. Unfortunately, these opportunities were limited in Malaysia given the need to respond to frequent changes in COVID-19-restrictions, making it difficult to establish relationships or effectively consider student feedback [47]. These results show that better communication strategies should be prioritized to improve student engagement in the classroom and incorporate student choice to promote relatedness and autonomy.

Developing competence is a priority to educators, given that the ultimate learning objectives of any programme are to develop student competencies. However, competence is also a component of self-determination and is intrinsic to the learning process, since only someone who is convinced about their ability to accomplish a task would be motivated to attempt the task [25, 26]. Here, perceptions about depth of learning and preparedness provided insight to students' self-perceived competence during the pandemic. Importantly, students indicated an overall satisfaction with their MBBS programmes and that the quality of their education has not been greatly changed. This suggests that there must be some degree of competence felt by the students. Comparatively, students responded that they are being under prepared for their profession and exhibited negative feelings towards formative feedback and 
the accuracy of some virtual assessments. These perceptions may relate to low self-confidence and difficulty interpreting their standings, likely leading to reduced feelings of competence [37,43]. This may have arisen since guidance to help students better understand their progression, which requires a social context, has likely been hindered during the pandemic [48-50]. Taken with the overall student satisfaction, competence in students likely exists, but may not be self-evident resulting in lowered motivation.

The self-determination profile of Malaysian medical students, as evidenced by the negative perceptions towards relatedness, autonomy, and competence, indicate an overall reduction of intrinsic motivation during the COVID-19 pandemic. More work is needed to determine the implications of these findings, but indicate that supports should be considered for each of the psychological needs to holistically mitigate the impacts of covid-related modifications on student motivation [44]. Further, as the pandemic resolves, student experiences will carryforward, impacting future learning and success if negative experiences are not remedied.

Perceptions about the COVID-19 pandemic were also evaluated for trends in sub-populations of students, with notable differences occurring between pre-clinical and clinical stages. While overall mental health and concern was similar between pre-clinical and clinical students, their learning experiences varied greatly. This is most attributed to the need for specific modifications from the different style of programme delivery for each group [8, 51, 52]. In Malaysia, preclinical students were transitioned to a virtual learning space, providing consistent, if not preferred, learning opportunities. This consistency may be why pre-clinical students more often felt that their overall well-being was being considered in the decision making of modifications. In contrast, pre-clinical students showed higher risk of depression and indicated that instructional delivery was less student-centered compared to clinical students. These perceptions may stem from the virtual wall if students have felt forgotten or isolated and may imply a reduction in autonomy and relatedness $[13,44,45]$. Conversely, clinical students were more affected by timing modifications, likely due to frequent changes to time, depth, or quality of clinical placements, and which have resulted in less satisfaction towards modifications made during the pandemic. The disruption to clinical teaching may also relate to their greater feelings of unpreparedness and concerns about securing housemanship positions, indicating a lowered sense of competency and to some degree of autonomy [8, 14, 53]. However, clinical students generally supported participation in clinical postings during the COVID-19 pandemic, and though some safety concerns or the ability to communicate their concerns were evident, this suggests that any reductions in motivation did not undermine the desire to contribute [54]. Different in experiences of pre-clinical and clinical students are expected, so characterizing them is useful to identify the specific needs of each group.

The diversity of students represented by the Malaysian medical student body provides an opportunity to explore whether there are ethnographic contributors to perceptions on educational experiences during the pandemic. This is of particular interest as the fundamental concepts of self-determination theory are universal, though there is less known about motivational profiles between demographic variables, particularly during the pandemic [37, 55]. Here, gender was related to the largest difference in experiences between students during the pandemic. Female students exhibited significantly worse mental health, perceived less depth of learning and student centredness, and were more concerned about delays on preparedness, implying reduced levels of intrinsic motivation. Since a recent Malaysian study reported no significant difference in online learning readiness during the pandemic between male and female students [56], these differences are not likely due to capabilities. Interestingly, prior to the pandemic, women have consistently expressed have a more self-determined profile than male counterparts, so it is curious which aspects of the pandemic-experience have contributed to these differences [27]. Given the similar life-stage of medical students in Malaysia, it is more likely that these feelings may arise from deeper internalization of concern, loneliness, and social separation, particularly given the striking difference in mental health [57-59]. Also, it is possible that female students who had returned home for virtual learning took on more household responsibilities. Globally, women have been disproportionately burdened with these responsibilities during the pandemic, which has attributed to different emotional responses of the genders [57,59]. The disparities between gender needs should be particularly highlighted during challenging times to provide appropriate support and ensure existing systemic biases are not exacerbated.

Ethnicity was also related to perceived experiences and motivational profiles of Malaysian medical students during the pandemic. The biggest difference arose in mental health and the impacts of change made to graduation. Interestingly, compared to their peers, Chinese students reported better mental health and were less concerned about family members developing COVID-19, perhaps indicating greater confidence during the pandemic. International students reported the lowest levels of mental health, which may be related to feelings of isolation if they are distanced from their native community or culture, since they also reported more concern

Page $12 / 18$ 
about family developing COVID-19. Interestingly, ethnicity was also related to perceptions about modifications made to graduation, as Indian students were least concerned about the impact of any delay. Attributing these findings to specific cultural norms would be inaccurate and insensitive in this context [55], but does indicate the need to ensure that all students, regardless of ethnicity, are properly supported, particularly in populations with such diverse representation.

Malaysian medical students from each income bracket are entitled to enter MBBS programmes through various streams including affordable, yet competitive, public universities, various funding initiatives, or more costly private universities [60]. Here, student groupings from different income brackets were found to have significantly different levels of concern, specifically those in the lowest income bracket who reported more concern about financial impacts from the pandemic. This may indicate a lower level of relatedness and autonomy, particularly if other students do not share the same concern or if additional costs may be incurred for virtual learning. They also indicated receiving less formative feedback, which may be related to technical issues. Indeed, it has been reported that, in addition to the fact that students in remote areas have faced technical challenges during remote learning, the economic impacts of the pandemic have disproportionately affected people in lower income groups [10]. Equity in education is essential and students from lower income bracket might need additional financial support in securing equal learning opportunities during the COVID-19 pandemic $[6,61]$. While alleviating financial constraints can be challenging, it is understood that institutions are trying to distribute resources to affected students, which would improve accessibility as well as helping students to feel validated.

Characterizing the experiences of medical students during the COVID-19 pandemic will help to develop inclusive strategies meant to mitigate any long-term impact caused by the pandemic-related modifications made to undergraduate medical education. This will, of course, require accommodation of diverse student needs and recognition that needs may be complicated by co-variates. While the scope of this study excludes a comprehensive analysis of how demographic features interact, we did find some demographic variances within subgroups. For example, Malay students in clinical stages expressed that they received more formative feedback and were more confident in their ability to voice safety concerns, which may relate to higher feelings of autonomy, despite average inclinations of students towards reduced communication during the pandemic. Some other differences were also seen within components of the survey, like feelings of preparedness or concerns about securing future positions, but more work is needed to better interpret these findings.

\section{Conclusions}

Taken together, these findings show how modifications made to medical education during the COVID-19 pandemic have impacted students, particularly in relation to mental health and other factors relating to self-determination. Overall, students expressed a lower level of motivation, as relatedness, autonomy, and competence were all affected by the changes. Within the Malaysian undergraduate medical student population, it is evident that student and demographic groups have experienced the pandemic differently, resulting in unique motivational profiles. Analyzing student experience is necessary to recognize how students have been uniquely affected and how educators can support them as they progress through their education and into the medical profession. Additionally, understanding the state of student well-being, experiences with learning, and ability to communicate during the pandemic, will help to better scaffold student learning. Ultimately, this study indicates that medical students across Malaysia have experienced relatively lower levels of self-determination during the COVID-19 pandemic.

\section{Abbreviations}

SOP: standard operating procedure; GAD: generalized anxiety disorder; MDD: major depressive disorder; SMMAMS: Society of Malaysian Medical Association Medical Students; AMEE: Association for Medical Education in Europe; C: component; KMO: KaiserMeyer Olkin; MBBS: bachelors of medicine and bachelor of surgery; MQA: Malaysian Qualifying Agency; MMC: Malaysian Medical Council

\section{Declarations}

\section{Ethics approval and consent to participate}


This research was reviewed and approved by the University Malaya Research Ethics Committee (UMREC) UM.TNC2/UMREC_1241. Informed consent was obtained from all subjects. All methods were carried out in accordance with relevant guidelines and regulations.

\section{Consent for publication}

All authors have read the manuscript and agreed to submission and publication.

\section{Availability of data and materials}

The datasets used and/or analysed during the current study are available from the corresponding author on reasonable request.

\section{Competing Interests}

The authors declare that they have no competing interests.

\section{Funding}

This work was supported in part by the UM-Liter grant RU013AF-2021.

\section{Author's contributions}

JGC, CY, DCPSC, TDJ, FCC, and HWH contributed to the design of the study, development of the survey and data interpretation. CY, DCPSC, and TDJ were responsible for data collection. JGC and FCC contributed to statistical design and analysis as well as manuscript preparation.

\section{Acknowledgments}

The authors would like to acknowledge Jamuna Vadivelu and Vinod Pallath, who advised on the development of the survey.

\section{References}

1. Zainuddin, A. CodeBlue. Kuala Lumpur October 8 2021,.

2. Aryffin Baharuddin, K.; Fuad, A.; Rahim, A.; Faridah, Y.; Aziz, A.; Manap, R.A.; Omar, A.M.; Singmamae, N.; Zulkifli, N.F.; Ismail, S.; et al. Association of Education in Medicine and Health Sciences Public Malaysian Medical Faculties during the COVID-19 Pandemic. Education in Medicine Journal 2020, 12, 25, doi:10.21315/eimj2020.12.4.4.

3. Sandars, J.; Correia, R.; Dankbaar, M.; de Jong, P.; Goh, P.S.; Hege, I.; Masters, K.; Oh, S.-Y.; Patel, R.; Premkumar, K.; et al. Twelve Tips for Rapidly Migrating to Online Learning during the COVID-19 Pandemic. MedEdPublish 2020, 9, doi:10.15694/mep.2020.000082.1.

4. Coiado, O.C.; Yodh, J.; Galvez, R.; Ahmad, K. How COVID-19 Transformed Problem-Based Learning at Carle Illinois College of Medicine. Medical Science Educator 2020, 30, 1353-1354, doi:10.1007/s40670-020-01063-3.

5. Alkhowailed, M.S.; Rasheed, Z.; Shariq, A.; Elzainy, A.; el Sadik, A.; Alkhamiss, A.; Alsolai, A.M.; Alduraibi, S.K.; Alduraibi, A.; Alamro, A.; et al. Digitalization Plan in Medical Education during COVID-19 Lockdown. Informatics in Medicine Unlocked 2020, 20, 100432, doi:10.1016/j.imu.2020.100432.

6. Foong, C.; Lye, A.; Aziz, C.; Hong, W.; Pallath, V.; Cockburn, J.; Rosli, S.; Krishnan, K.; Sivalingam, P.; Zulkepli, N.; et al. Learning Experiences of Pre-Clinical Medical Students in Virtual Problem-Based Learning amidst the COVID-19 Pandemic. The AsianPacific Scholar 2021.

7. Anderson, T. The Theory and Practice of Online Learning; Anderson, T., Ed.; 2nd ed.; AU Press: Edmonton, 2008;

8. Ferrel, M.N.; Ryan, J.J. The Impact of COVID-19 on Medical Education. Cureus 2020, 12, doi:10.7759/cureus.7492.

9. Khalil, R.; Mansour, A.E.; Fadda, W.A.; Almisnid, K.; Aldamegh, M.; Al-Nafeesah, A.; Alkhalifah, A.; Al-Wutayd, O. The Sudden Transition to Synchronized Online Learning during the COVID-19 Pandemic in Saudi Arabia: A Qualitative Study Exploring Medical Students' Perspectives. BMC Medical Education 2020, 20, 285, doi:10.1186/s12909-020-02208-z. 
10. Surkhali, B.; Garbuja, C.K. Virtual Learning during COVID-19 Pandemic: Pros and Cons. Journal of Lumbini Medical College 2020, 8, 154-155, doi:10.22502/JLMC.V8I1.363.

11. Longhurst, G.; Stone, D.; Dulohery, K.; Scully, D.; Campbell, T.; Smith, C. Strength, Weakness, Opportunity, Threat (SWOT) Analysis of the Adaptations to Anatomical Education in the United Kingdom and Republic of Ireland in Response to the Covid-19 Pandemic. Anatomical Sciences Education 2020, 13, 301-311, doi:10.1002/ASE.1967.

12. Hameed, T.; Husain, M.; Jain, S.K.; Singh, C.B.; Khan, S. Online Medical Teaching in COVID-19 Era: Experience and Perception of Undergraduate Students. Mædica 2020, 15, 440, doi:10.26574/MAEDICA.2020.15.4.440.

13. Wilcha, R.-J. Effectiveness of Virtual Medical Teaching During the COVID-19 Crisis: Systematic Review. JMIR Medical Education 2020, 6, doi:10.2196/20963.

14. Halbert, J.A.; Jones, A.; Ramsey, L.P. Clinical Placements for Medical Students in the Time of COVID-19. Medical Journal of Australia 2020, 213, 69-69.e1.

15. Choi, B.; Jegatheeswaran, L.; Minocha, A.; Alhilani, M.; Nakhoul, M.; Mutengesa, E. The Impact of the COVID-19 Pandemic on Final Year Medical Students in the United Kingdom: A National Survey. BMC Medical Education 2020, 20, doi:10.1186/S12909020-02117-1.

16. Kim, S.M.; Park, S.G.; Jee, Y.K.; Song, I.H. Perception and Attitudes of Medical Students on Clinical Clerkship in the Era of the Coronavirus Disease 2019 Pandemic. Medical Education Online 2020, 25, doi:10.1080/10872981.2020.1809929.

17. Wong, R.Y. Medical Education during COVID-19: Lessons from a Pandemic. BCMJ 2020, 62, 170-171.

18. Moh Dat, N.; Mardihiyyah Alwi, N.S.; Aziz, A.; Anhar Holder, N.A.K.; Hong, W.-H.; Vadivelu, J.; Cockburn, J.G. What Happens PostPandemic?: Adaptation of Assessment in University Malaya Medical Programme (UMMP). In Proceedings of the Knovasi: Evolution Towards Borderless Learning, A Way Forward; Pusat Pengajaran \& Pembangunan Kurikulum: Selangor, August 17 2021; pp. 240-243.

19. Choi, B.; Jegatheeswaran, L.; Minocha, A.; Alhilani, M.; Nakhoul, M.; Mutengesa, E. The Impact of the COVID-19 Pandemic on Final Year Medical Students in the United Kingdom: A National Survey. BMC Medical Education 2020, 20, doi:10.1186/s12909020-02117-1.

20. Taylor, D.; Grant, J.; Hamdy, H.; Grant, L.; Marei, H.; Venkatramana, M. Transformation to Learning from a Distance. MedEdPublish 2020, 9, doi:10.15694/mep.2020.000076.1.

21. Newman, N.A.; Lattouf, O.M. Coalition for Medical Education-A Call to Action: A Proposition to Adapt Clinical Medical Education to Meet the Needs of Students and Other Healthcare Learners during COVID-19. Journal of Cardiac Surgery 2020, 35, 1174-1175.

22. Leal Filho, W.; Wall, T.; Rayman-Bacchus, L.; Mifsud, M.; Pritchard, D.J.; Lovren, V.O.; Farinha, C.; Petrovic, D.S.; Balogun, A.-L. Impacts of COVID-19 and Social Isolation on Academic Staff and Students at Universities: A Cross-Sectional Study. BMC Public Health 2021 21:1 2021, 21, 1-19, doi:10.1186/S12889-021-11040-Z.

23. Al-Balas, M.; Al-Balas, H.I.; Jaber, H.M.; Obeidat, K.; Al-Balas, H.; Aborajooh, E.A.; Al-Taher, R.; Al-Balas, B. Distance Learning in Clinical Medical Education amid COVID-19 Pandemic in Jordan: Current Situation, Challenges, and Perspectives. BMC Medical Education 2020, 20, doi:10.1186/s12909-020-02257-4.

24. Slivkoff, M.D.; Johnson, C.; Tackett, S. First-Year Medical Student Experiences Adjusting to the Immediate Aftermath of COVID19. Medical Science Educator 2021, 31, 1, doi:10.1007/S40670-021-01213-1.

25. Ryan, R.M.; Deci, E.L. Self-Determination Theory and the Facilitation of Intrinsic Motivation, Social Development, and Well-Being Self-Determination Theory. American Psychologist 2000, 55, 68-78.

26. Cate, O.Th.J. ten; Kusurkar, R.A.; Williams, G.C. How Self-Determination Theory Can Assist Our Understanding of the Teaching and Learning Processes in Medical Education. AMEE Guide No. 59. https://doiorg.ezproxy.um.edu.my/10.3109/0142159X.2011.595435 2012, 33, 961-973, doi:10.3109/0142159X.2011.595435.

27. Orsini, C.; Binnie, V.I.; Wilson, S.L. Determinants and Outcomes of Motivation in Health Professions Education: A Systematic Review Based on Self-Determination Theory. Journal of Educational Evaluation for Health Professions 2016, 13, 19, doi:10.3352/JEEHP.2016.13.19.

28. Šakan, D.; Žuljević, D.; Rokvić, N. The Role of Basic Psychological Needs in Well-Being During the COVID-19 Outbreak: A SelfDetermination Theory Perspective. Frontiers in Public Health 2020, 0, 713, doi:10.3389/FPUBH.2020.583181.

Page $15 / 18$ 
29. Wang, X.; Zhang, R.; Wang, Z.; Li, T. How Does Digital Competence Preserve University Students' Psychological Well-Being During the Pandemic? An Investigation From Self-Determined Theory. Frontiers in Psychology 2021, 0, 1252, doi:10.3389/FPSYG.2021.652594.

30. Artino, A.R.; la Rochelle, J.S.; Dezee, K.J.; Gehlbach, H. Developing Questionnaires for Educational Research: AMEE Guide No. 87. Medical Teacher 2014, 36, 463-474, doi:10.3109/0142159X.2014.889814.

31. Kroenke, K.; Spitzer, R.; Williams, J.; Monahan, P.; Löwe, B. Anxiety Disorders in Primary Care: Prevalence, Impairment, Comorbidity, and Detection. Annals of internal medicine 2007, 146, 317-325, doi:10.7326/0003-4819-146-5-200703060-00004.

32. Kroenke, K.; Spitzer, R.; Williams, J. The Patient Health Questionnaire-2: Validity of a Two-Item Depression Screener. Medical care 2003, 41, 1284-1292, doi:10.1097/01.MLR.0000093487.78664.3C.

33. Bowling, A. Public Health-Research-Methodology; 2009; Vol. 362;.

34. Braun, V.; Clarke, V. Using Thematic Analysis in Psychology. Qualitative Research in Psychology 2006, 3, 77-101, doi:10.1191/1478088706QP0630A.

35. Zafar, S.M.A.; Tahir, M.J.; Malik, M.; Malik, M.I.; Akhtar, F.K.; Ghazala, R. Awareness, Anxiety, and Depression in Healthcare Professionals, Medical Students, and General Population of Pakistan during COVID-19 Pandemic: A Cross Sectional Online Survey. Medical Journal of the Islamic Republic of Iran 2020, 34, 131, doi:10.34171/MJIRI.34.131.

36. Cherak, S.J.; Brown, A.; Kachra, R.; Makuk, K.; Sudershan, S.; Paget, M.; Kassam, A. Exploring the Impact of the COVID-19 Pandemic on Medical Learner Wellness: A Needs Assessment for the Development of Learner Wellness Interventions. Canadian Medical Education Journal 2021, 12, 54, doi:10.36834/CMEJ.70995.

37. Neufeld, A.; Malin, G. Exploring the Relationship between Medical Student Basic Psychological Need Satisfaction, Resilience, and Well-Being: A Quantitative Study. BMC Medical Education 2019, 19, doi:10.1186/S12909-019-1847-9.

38. ATasso, A.; Hisli Sahin, N.; San Roman, G. COVID-19 Disruption on College Students: Academic and Socioemotional Implications. Psychological trauma: theory, research, practice and policy 2021, 13, 9-15, doi:10.1037/TRA0000996.

39. Cherak, S.J.; Rosgen, B.K.; Geddes, A.; Makuk, K.; Sudershan, S.; Peplinksi, C.; Kassam, A. Wellness in Medical Education: Definition and Five Domains for Wellness among Medical Learners during the COVID-19 Pandemic and Beyond. Medical Education Online 2021, 26, doi:10.1080/10872981.2021.1917488.

40. Schlesselman, L.S.; Cain, J.; DiVall, M. Improving and Restoring the Well-Being and Resilience of Pharmacy Students during a Pandemic. American Journal of Pharmaceutical Education 2020, 84, 677-682, doi:10.5688/AJPE8144.

41. Niemiec, C.P.; Ryan, R.M. Autonomy, Competence, and Relatedness in the Classroom. Theory and Research in Education 2009, 7, 133-144, doi:10.1177/1477878509104318.

42. Zorn, C.; Feffer, M.-L.; Bauer, É.; Dillenseger, J.-P. Évaluation d’un Dispositif de Continuité Pédagogique à Distance Mis En Place Auprès d'étudiants MERM Pendant Le Confinement Sanitaire Lié Au COVID-19. Journal of Medical Imaging and Radiation Sciences 2020, 51, 645, doi:10.1016/J.JMIR.2020.08.020.

43. Vergara-Torres, A.P.; Tristán, J.; López-Walle, J.M.; González-Gallegos, A.; Pappous, A. (Sakis); Tomás, I. Students' Perceptions of Teachers' Corrective Feedback, Basic Psychological Needs and Subjective Vitality: A Multilevel Approach. Frontiers in Psychology 2020, 11, doi:10.3389/FPSYG.2020.558954.

44. Rashid, M.; Guo, Q.; Babenko, O. The Influence of Students' Perceptions of Learning Environment on Coping with Academic Challenges: A Structural Equation Modeling Study. Teaching and Learning in Medicine 2019, 32, 204-217, doi:10.1080/10401334.2019.1667241.

45. Firat, M. Measuring the E-Learning Autonomy of Distance Education Students. Open Praxis 2016, 8, 191-201, doi:10.3316/INFORMIT.283387304091560.

46. Yuksel, U. Integrating Curriculum: Developing Student Autonomy In Learning In Higher Education. Journal of College Teaching \& Learning (TLC) 2010, 7, 1, doi:10.19030/TLC.V718.138.

47. Hashim, J.H.; Adman, M.A.; Hashim, Z.; Mohd Radi, M.F.; Kwan, S.C. COVID-19 Epidemic in Malaysia: Epidemic Progression, Challenges, and Response. Frontiers in Public Health 2021, 0, 247, doi:10.3389/FPUBH.2021.560592.

48. Chaker, R.; Impedovo, M.A. The Moderating Effect of Social Capital on Co-Regulated Learning for MOOC Achievement. Education and Information Technologies 2021, 26, 1, doi:10.1007/S10639-020-10293-2. 
49. JV, R. Proposing a Model of Co-Regulated Learning for Graduate Medical Education. Academic medicine: journal of the Association of American Medical Colleges 2017, 92, 1100-1104, doi:10.1097/ACM.0000000000001583.

50. Bransen, D.; Govaerts, M.J.B.; Sluijsmans, D.M.A.; Driessen, E.W. Beyond the Self: The Role of Co-regulation in Medical Students' Self-regulated Learning. Medical Education 2020, 54, 234, doi:10.1111/MEDU.14018.

51. Dhillon, J.; Salimi, A.; ElHawary, H. Impact of COVID-19 on Canadian Medical Education: Pre-Clerkship and Clerkship Students Affected Differently. Journal of Medical Education and Curricular Development 2020, 7, 238212052096524, doi:10.1177/2382120520965247.

52. Sandhu, P.; de Wolf, M. The Impact of COVID-19 on the Undergraduate Medical Curriculum. Medical Education Online 2020, 25.

53. Akers, A.; Blough, C.; Iyer, M.S. COVID-19 Implications on Clinical Clerkships and the Residency Application Process for Medical Students. Cureus 2020, 12, doi:10.7759/CUREUS.7800.

54. Park, J.J. Medical Student Perceptions of Working in Clinical Environments during the COVID-19 Pandemic. Journal of Global Health 2020, 10, doi:10.7189/JOGH.10.020380.

55. SHELDON, K.M. The Self-Determination Theory Perspective on Positive Mental Health across Cultures. World Psychiatry 2012, 11, 101, doi:10.1016/J.WPSYC.2012.05.017.

56. Chung, E.; Subramaniam, G.; Dass, laura C. Online Learning Readiness among University Students in Malaysia amidst COVID19, Asian Journal of University Education, 2020-Jul. Asian Journal of University Education 2020, 16, 46-58.

57. Abreu, L.; Koebach, A.; Díaz, O.; Carleial, S.; Hoeffler, A.; Stojetz, W.; Freudenreich, H.; Justino, P.; Brück, T. Life With Corona: Increased Gender Differences in Aggression and Depression Symptoms Due to the COVID-19 Pandemic Burden in Germany. Frontiers in Psychology 2021, 12, doi:10.3389/FPSYG.2021.689396.

58. Ettman, C.K.; Abdalla, S.M.; Cohen, G.H.; Sampson, L.; Vivier, P.M.; Galea, S. Prevalence of Depression Symptoms in US Adults Before and During the COVID-19 Pandemic. JAMA Network Open 2020, 3, doi:10.1001/JAMANETWORKOPEN.2020.19686.

59. Connor, J.; Madhavan, S.; Mokashi, M.; Amanuel, H.; Johnson, N.R.; Pace, L.E.; Bartz, D. Health Risks and Outcomes That Disproportionately Affect Women during the Covid-19 Pandemic: A Review. Social Science \& Medicine (1982) 2020, 266, 113364, doi:10.1016/J.SOCSCIMED.2020.113364.

60. Lim, Dr.V.K.E. Medical Education in Malaysia. https://doi.org/10.1080/01421590801942102 2009, 30, 119-123, doi:10.1080/01421590801942102.

61. Thomson, S. Achievement at School and Socioeconomic Background-an Educational Perspective. npj Science of Learning 2018 3:1 2018, 3, 1-2, doi:10.1038/s41539-018-0022-0.

\section{Figures}

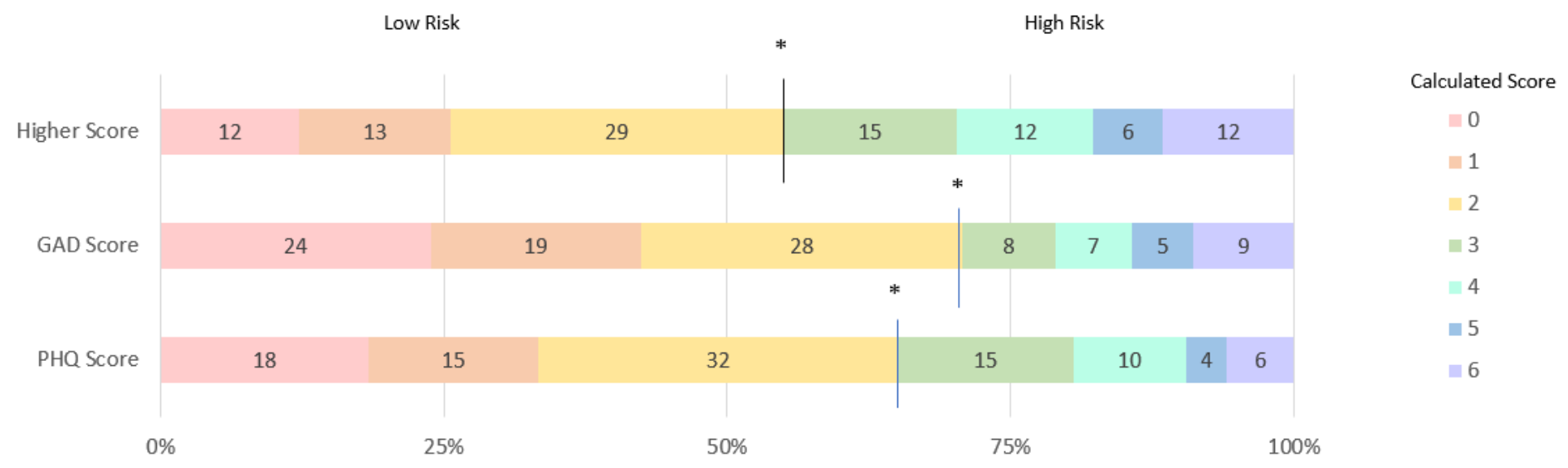

Frequency of Scores

(\%)

Page $17 / 18$ 


\section{Figure 1}

Distribution of PHQ and GAD scores amongst all students, given in percent of total student population. Combined higher scores indicate total number of students at risk of MDD or GAD, specifically those with either GAD or PHQ score $\geq 3$.

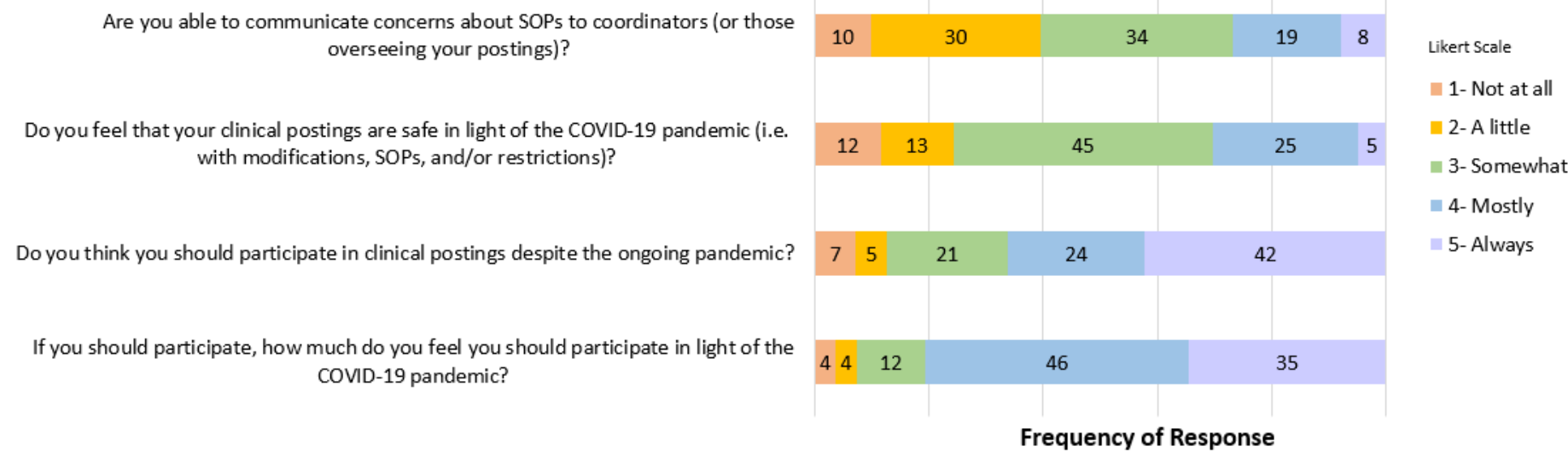

(\%)

Figure 2

Clinical student responses indicate some concern regarding ability to communicate safety concerns, but an overall inclination towards participation. *risk threshold

\section{Supplementary Files}

This is a list of supplementary files associated with this preprint. Click to download.

- AdditionalFile1.xlsx 